\title{
Fibroblast Growth Factor 2 Dimer with Superagonist In Vitro Activity Improves Granulation Tissue Formation During Wound Healing
}

Caitlin G. Decker ${ }^{\mathrm{a}}$, Yu Wang ${ }^{\mathrm{e}}$, Samantha J. Paluck ${ }^{\mathrm{a}}$, Lu Shen ${ }^{\mathrm{a}}$, Joseph A. Loo ${ }^{\mathrm{ab}}$, Alex J. Levine $^{\text {acd }}$, Lloyd S. Miller ${ }^{\mathrm{e}}$, and Heather D. Maynard ${ }^{\mathrm{a}^{*}}$

${ }^{a}$ Department of Chemistry and Biochemistry and California NanoSystems Institute, University of California, Los Angeles, 607 Charles E. Young Drive South, Los Angeles, California 90095-1569, United States

${ }^{\mathrm{b}}$ Department of Biological Chemistry, David Geffen School of Medicine, and UCLA/DOE Institute of Genomics and Proteomics, University of California, Los Angeles, California 90095, United States

${ }^{c}$ Department of Physics and Astronomy, University of California, Los Angeles, California 90095-1569, United States

${ }^{\mathrm{d}}$ Department of Biomathematics, University of California, Los Angeles, California 90095-1569, $\quad$ United $\quad$ States ${ }^{\mathrm{e}}$ Department of Dermatology, Johns Hopkins University School of Medicine, 1550 Orleans St., Baltimore, MD, 21231, United States

Abbreviated Title: FGF2 Dimer Improves Granulation Tissue Formation

*To whom correspondence should be addressed: maynard@chem.ucla.edu Phone: +1 (310) 267-5162 Fax: +1 (310) 206-4038

C 2015. This manuscript version is made available under the Elsevier user license http://www.elsevier.com/open-access/userlicense/1.0/ 


\begin{abstract}
:
Site-specific chemical dimerization of fibroblast growth factor 2 (FGF2) with the optimal linker length resulted in a FGF2 homodimer with improved granulation tissue formation and blood vessel formation at exceptionally low concentrations. Homodimers of FGF2 were synthesized through site-specific linkages to both ends of different molecular weight poly(ethylene glycols) (PEGs). The optimal linker length was determined by screening dimer-induced metabolic activity of human dermal fibroblasts and found to be that closest to the inter-cysteine distance, $70 \AA$, corresponding to $2 \mathrm{kDa}$ PEG. A straightforward analysis of the kinetics of second ligand binding as a function of tether length showed that, as the polymerization index (the number of monomer repeat units in the polymer, $\mathrm{N}$ ) of the tether decreases, the mean time for second ligand capture decreases as $\sim \mathrm{N}^{3 / 2}$, leading to an enhancement of the number of doubly bound ligands in steady-state for a given (tethered) ligand concentration. FGF2-PEG2k-FGF2 induced greater fibroblast metabolic activity than FGF2 alone, all other dimers, and all monoconjugates, at each concentration tested, with the greatest difference observed at low $(0.1 \mathrm{ng} / \mathrm{mL})$ concentration. FGF2-PEG2k-FGF2 further exhibited superior activity compared to FGF2 for both metabolic activity and migration in human umbilical vein endothelial cells, as well as improved angiogenesis in a coculture model in vitro. Efficacy in an in vivo wound healing model was assessed in diabetic mice. FGF2PEG2k-FGF2 increased granulation tissue and blood vessel density in the wound bed compared to FGF2. The results suggest that this rationally designed construct may be useful for improving the fibroblast matrix formation and angiogenesis in chronic wound healing.
\end{abstract}


Keywords: wound healing, diabetic wounds, growth factor, PEGylation, dimerization, angiogenesis

\section{Introduction}

Healing in chronic wounds including venous, arterial, diabetic[1], and pressure[2] ulcers is impaired due to decreased growth factor production, keratinocyte and fibroblast proliferation and migration, granulation tissue formation, and angiogenesis. Treatment of chronic wounds costs over 9.5 billion U.S. dollars annually, worldwide.[3] Diabetes alone is projected to affect 439 million adults (ages 20-79) by 2030 globally, and $15 \%$ of diabetic patients develop chronic foot ulcers[4]. Thus, viable treatment of chronic wounds represents a significant challenge to the medical community.

Fibroblast growth factor 2 (FGF2), a growth factor whose expression is impaired in both diabetic and pressure ulcers, $[1,2]$ moderates cell proliferation, differentiation and migration of multiple cell types. FGF2 is critical in wound healing, angiogenesis, bone regeneration, neuroregeneration, and can even result in scarless healing $[5,6]$. As a result FGF2 released from gels alone or in combination with other proteins and/or heparin has been employed as a strategy to increase angiogenesis, ischemic heart repair, nerve regeneration, etc. in vivo.[7-10] While FGF2 alone appears to be a good candidate for the treatment of chronic wounds, and is approved in Japan (Fiblast or Trafermin) for skin ulcers, US and European clinical trials (Phase II for treatment of peripheral arterial[11] and coronary[12] disease and Phase III for neuropathic diabetic foot ulcers[13], respectively) have shown minimal effectiveness[14]. Thus, increasing the effectiveness 
of FGF2 is an important endeavor. This has been undertaken by a variety of approaches, including adding peptides or proteins that bind to both FGF2 and its receptor,[17-19] by truncating the FGF2 sequences[20], mutating specific amino acid residues[21, 22], covalent modification,[23-25] or by utilizing FGF receptor peptide agonists as an alternative.[26, 27] In this report, we describe the formation of an FGF2 with superagonist activity in vitro that improves granulation tissue formation and blood vessel density during wound healing in vivo at low doses through chemical dimerization of FGF2.

FGF2 activity is dependent on the formation of a tetrameric complex, consisting of two FGF2 proteins and two FGF receptors (FGFR1)[28, 29]. Many proteins, like FGF2, exist or self-assemble into homodimers or multimers in their native or active state and these structures are often required for protein activity[30, 31]. Synthetic routes to protein dimerization are pursued in the scientific community as a means to study protein interactions and to create superagonist growth factor therapeutics[32-35]. Preorganization of dimeric ligands is known to increase the effective local concentrations, thereby facilitating activation of receptors[36, 37]. Heparin or oligoheparins are mimics of membrane-bound heparin-sulfates that are known to facilitate FGF2 receptor binding and dimerization. It has been shown that adding heparin, [38, 39] or oligoheparins[40-42] is important for FGF2 activity, and it is has been proposed that the heparin molecules promote FGF2 dimerization in heparanoid complexes.[43] Nonspecific chemical crosslinking of FGF2 lysine side-chains through reaction with short (11.4 $\mathrm{A})[23-25]$ tethers such as bis(sulfosuccinimidyl) suberate has been performed as a means to study the interaction of FGF2 with heparin oligomers. Towards the same end FGF2 has also 
been oligomerized through biotin-streptavidin binding[44]. In addition, recombinant expression of a dimeric FGF2 has led to enhanced biological activity compared to FGF2 alone[45]. While these prior reports nicely demonstrate the importance of dimerization of FGF2, we hypothesized that much more significant activity could be obtained by 1) conjugating site-selectively to residues spatially separated from both the heparin-binding domain and receptor binding sites and 2) probing the ideal length of the dimerizer.

Site-specific conjugation is imperative in the development of protein homodimers in order to avoid the formation of protein multimers or complex protein-polymer networks. In addition, polymer conjugation at or near an active site, or the addition of multiple polymers to a protein therapeutic can shut down protein activity[46]. Therefore targeting a single reactive site is important to maintain protein activity. Cysteine is an ideal target for site-specific protein modification due to its low abundance and nucleophilicity[47]. FGF2 contains two surface-exposed free cysteines (Cys-78 and Cys96)[48]. The mutation of either cysteine, as shown by Lappi et al, is not detrimental to protein activity[49], and Kang et al observed a retention of activity after PEGylation at both surface-exposed cysteines with a $5 \mathrm{kDa}$ PEG[48]. Therefore we chose to install the genetic modification cysteine to serine at amino acid 78 (C78S), resulting in an FGF2 containing a single surface-exposed cysteine, Cys96 (shown in red, Figure 1).

In addition to site-selective dimerization, the length of the tether is also imperative to protein activity. Linker length is essential to receptor activation for similar growth factors[32, 35, 36]. Based on the crystal structure of the tetrameric FGF2:FGFR1 complex, we hypothesized that a flexible linker with a length close to the inter-cysteine distance of $70 \AA$ would induce the greatest activity[28, 29]. Poly(ethylene glycol) (PEG) 
was chosen as the linker based on the ease of modification. PEG is also known to improve pharmacokinetics through stabilization and improved circulation time, and many FDA-approved, PEGylated therapeutic agents are on the market[50, 51]. In addition, there have been several PEG-FGF2 monoconjugates prepared that have improved circulation life times and other favorable in vivo features such as enhanced penetration into the injured spinal cord.[52-56] Here, we describe the development of PEG-linked FGF2 dimers as superagonists that could be used to create a more fertile wound healing bed.

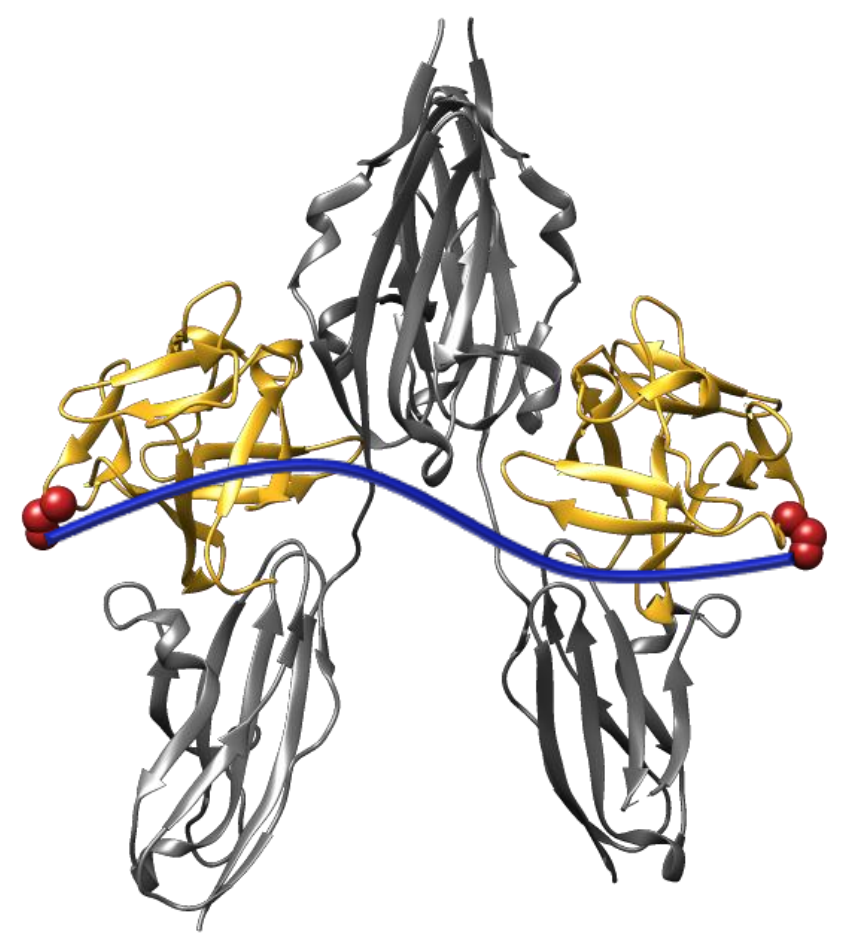

Figure 1. The active tetrameric complex consisting of two FGF2s (gold) two FGFRs (silver) with Cys96 in red and poly(ethylene glycol) represented in blue. Modified from PDB 1CVS using Chimera software. 


\section{Materials and Methods}

\subsection{Materials}

All chemicals and reagents were purchased from Sigma-Aldrich and used as received unless otherwise indicated. Enzyme-linked immunosorbent assay (ELISA) Development DuoSet kit was purchased from R\&D Systems. Normal Human Dermal Fibroblasts (HDFs), HUVECs, and cell media were purchased from ATCC.

\subsection{HDF Metabolic activity Assay}

HDF cells (passage 4 - ATCC) were suspended in UltraCULTURE ${ }^{\mathrm{TM}}$ (Lonza) serum-free medium supplemented with $2 \mathrm{mM}$ L-Glutamine, $100 \mu \mathrm{g} / \mathrm{ml}$ penicillin, and $100 \mu \mathrm{g} / \mathrm{ml}$ streptomycin, and plated at 2000 cells/well in a 96-well plate. The cells were allowed to adhere for 16 hours at $37{ }^{\circ} \mathrm{C}, 5 \% \mathrm{CO}_{2}$. After 16 hours the medium was removed by aspiration and replaced with $100 \mu \mathrm{L}$ of unmodified FGF2, mPEG-FGF2, or FGF2-PEGFGF2, diluted in UltraCULTURE ${ }^{\mathrm{TM}}$ medium (original concentration determined by ELISA). The cells were incubated with the samples for 72 hours at $37{ }^{\circ} \mathrm{C}, 5 \% \mathrm{CO}_{2}$ without media exchange, after which cell metabolic activity was assessed using a CellTiter-Blue $^{\circledR}$ assay. All experimental groups were normalized to the control group, which received only blank medium. Each group was done with six replicates.

\subsection{HUVEC Metabolic activity Assay}


HUVEC cells (passage 5 - ATCC) were suspended in $\mathrm{EGM}^{\mathrm{TM}}$ (-BBE) medium supplemented with $100 \mathrm{ug} / \mathrm{ml}$ penicillin and $100 \mu \mathrm{g} / \mathrm{ml}$ streptomycin, and plated at 1000 cells/well in a 96-well plate. The cells were allowed to adhere for 16 hours at $37{ }^{\circ} \mathrm{C}, 5 \%$ $\mathrm{CO}_{2}$. After 16 hours the medium was removed by aspiration and replaced with $100 \mu \mathrm{L}$ of unmodified FGF2, mPEG-FGF2, or FGF2-PEG-FGF2 (protein concentration determined by ELISA) diluted in epidermal growth medium without bovine brain extract $\left(\mathrm{EGM}^{\mathrm{TM}}-\right.$ BBE). The cells were incubated with the samples for 72 hours at $37^{\circ} \mathrm{C}, 5 \% \mathrm{CO}_{2}$ without media exchange, after which cell metabolic activity was assessed using a CellTiter-Blue ${ }^{\circledR}$ assay. All experimental groups were normalized to the control group, which received only blank medium. Each group was done with six replicates

\subsection{HDF Migration Assay}

Two horizontal lines were drawn on the back of each well of a $0.2 \%$ gelatin-coated 24well plate. HDFs from ATCC (P4) were seeded in fibroblast growth medium with full supplements at 70,000 cells/well (400 $\mu \mathrm{L} /$ well) and allowed to incubate for 24 hours at $37{ }^{\circ} \mathrm{C}, 5 \% \mathrm{CO}_{2}$. The media was then removed, and the wells rinsed with warm D-PBS $2 \mathrm{x}$, followed by the addition of starvation media, DMEM $+2 \%$ FBS and the cells incubated for 24 hours. A vertical scratch was then made using a P200 pipette tip. The wells were then rinsed $2 \mathrm{x}$ with warm D-PBS, and then the diluted samples of FGF2 or FGF2-PEG2k-FGF2 (in DMEM + 2\% FBS) were added into 4 wells per concentration $\left(\mathrm{n}_{\max }=8\right)$ as well as 4 wells containing blank media. The cells were then incubated for 18 hours. Bright field images were taken just above and just below each drawn line, and analyzed using ImageJ, by measuring the distance (pixels) of the cell-free area at $\mathrm{T}=0$ and 
$\mathrm{T}=18$. The study was blinded before image analysis. Cell images were taken in bright field with a Zeiss Axioscope equipped with an AxioCam MRm at 5x magnification.

\subsection{HUVEC Migration Assay}

Two horizontal lines were drawn on the back of each well of a $0.2 \%$ gelatin-coated 24well plate. HUVECs (P5) were seeded in complete Epidermal Growth Media (EGM), at 60,000 cells/well (400 $\mu \mathrm{L} /$ well) and allowed to incubate for 24 hours at $37{ }^{\circ} \mathrm{C}, 5 \% \mathrm{CO}_{2}$. The media was then removed, and the wells rinsed with warm D-PBS $2 x$, followed by the addition of starvation media, DMEM $+2 \%$ FBS and the cells incubated for 24 hours. A vertical scratch was then made using a P200 pipette tip. The wells were then rinsed 2x with warm D-PBS, and then samples diluted in DMEM $+2 \%$ FBS, were added at each concentration into 4 separate wells, as well as 4 wells of blank media. The cells were then incubated for 18 hours. Pictures were taken at $5 \mathrm{X}$ magnification at $\mathrm{T}=0$ and $\mathrm{T}=18$ hours. Bright field images were taken just above and just below each drawn line, and analyzed using ImageJ, by measuring the distance (pixels) of the cell-free area at $\mathrm{T}=0$ and $\mathrm{T}=18$. One of the two full repeats was blinded before image analysis.

\subsection{In vitro Angiogenesis Co-Culture Assay}

Methods for angiogenesis co-culture and cord-like structure staining were adapted from literature procedures[57, 58]. HDFs (P3) were plated at 12,500 cells/well in a 48-well plate, in endothelial growth medium (EGM) with full supplement and incubated at $37^{\circ} \mathrm{C}$ for 72 hours or until cells reached confluency. The cells were then starved for 18 hours with EGM (-BBE) minus epidermal growth factor (-EGF). HUVECs (P4) were 
trypsonized and resuspended in EGM (-BBE) (-EGF). Starvation media was aspirated and HUVECs were plated on top of the HDF monolayer at 10,000 cells/well in EGM (BBE) (-EGF) followed by sample (either FGF2 or FGF2-PEG2k-FGF2) diluted in EGM (-BBE) (-EGF). Final concentrations of FGF2 and FGF2-PEG2k-FGF2 were $10 \mathrm{ng} / \mathrm{mL}$, $5 \mathrm{ng} / \mathrm{mL}, 1 \mathrm{ng} / \mathrm{mL}, 0.5 \mathrm{ng} / \mathrm{mL}$, and $0.1 \mathrm{ng} / \mathrm{mL}$. After 72 and 144 hours the sample solutions were refreshed with samples EGM (-BBE) (-EGF) at the appropriate concentrations. Ten days after HUVEC and the first sample addition, the medium was removed and each well fixed with $70 \% \mathrm{EtOH}\left(\right.$ at $-20^{\circ} \mathrm{C}$ ) for 30 minutes. After fixing, the wells were rinsed with $0.5 \mathrm{~mL}$ of $1 \%$ BSA in D-PBS three times. Next, endogenous alkaline phosphatase was removed by incubation with $0.3 \% \mathrm{H}_{2} \mathrm{O}_{2}$ in $\mathrm{MeOH}$ at room temperature for 15 minutes. The $\mathrm{H}_{2} \mathrm{O}_{2}$ solution was removed once the solution was cloudy. The wells were washed 3 times with $1 \%$ BSA. The wells were then incubated with primary antibody (mouse anti-human PECAM1/CD31, R\&D Systems) at $1 \mathrm{ug} / \mathrm{mL}$ in $1 \%$ BSA for 60 minutes at $37^{\circ} \mathrm{C}$. The wells were then rinsed 3 times with $1 \%$ BSA. The wells were then incubated with secondary antibody (goat anti-mouse IgG - alkaline phosphatase, Sigma Aldrich) at $3 \mathrm{ug} / \mathrm{mL}$ in $1 \%$ BSA for 60 minutes at $37{ }^{\circ} \mathrm{C}$ and then wells were rinsed $3 \times 5$ minutes with milliQ water. Next, the wells were incubated with BCIP/NBT solution (one tablet dissolved in $10 \mathrm{~mL}$ milliQ water, filtered) at room temperature for 6-15 minutes. After the cord-like structures were visually stained, the BCIP/NBT (Life Technologies) was removed and the wells were washed 3 times with milliQ water and allowed to dry. Plates were stored for up to 60 days at $-80^{\circ} \mathrm{C}$. To assess the extent of angiogenesis, 5 bright field images were captured per well at $5 \mathrm{x}$ magnification. Number and length of the cord-like structures as well as number of nodes 
were calculated manually using NIH ImageJ Software. The values for each of 5 images per well were summed and then the sums were averaged across 3 wells. The sample identities remained blinded during analysis and until after results were calculated. An example of how the structures were counted is provided in the Supporting Information.

\subsection{Animal Use Ethics Statement}

All animals were handled in strict accordance with good animal practice as defined in the federal regulations as set forth in the written Assurance of Compliance with PHS Policy to the United States Department of Health and Human Services (Assurance No. A307901) and Regulations of the Animal Welfare Act of the United States Department of Agriculture (USDA registration \#23-R-0023). All animal work was approved by the Johns Hopkins University Animal Care and Use Committee (ACUC Protocol No. MO12M465) and the animal care program at the Johns Hopkins School of Medicine is fully accredited by the Association for Assessment and Accreditation of Laboratory Animal Care International (AAALAC).

\subsection{In vivo Assessment of Wound Healing in Diabetic Mice}

Eight to nine-week-old male TallyHo/JngJ mice (Jackson Laboratories, Bar Harbor, ME) were used as a model of type II diabetes. Briefly, 1 day prior to wounding, dorsal hair was shaved and depilated and mice were housed individually. Full-thickness wounds were created on the dorsum of mice ( $8 \mathrm{~mm}$ punch biopsy; Acuderm, Inc., Lauderdale, FL). The wound bed was covered with Tegaderm ${ }^{\mathrm{TM}}(3 \mathrm{M}$, St. Paul, MN) and treated with

$20 \mu 1$ of FGF2 or FGF2-PEG2k-FGF2 (0.02 $\mu$ g total) or D-PBS control $\left(-\mathrm{Mg}^{2+},-\mathrm{Ca}^{2+}\right)$ by 
injecting through the covering into the wound bed once daily for 5 days. The covering was removed on day 7. Digital photographs taken on day $0,1,2,3,4,7,10$, and 14 and wound area was measured using ImageJ software. The wound beds were excised en bloc with the surrounding soft tissue and fixed with $10 \%$ formalin solution and histologic analysis was performed on day 14 . The granulation tissue area and blood vessel density were measured as previously described[59]. The procedures were conducted blinded.

\section{Results}

\subsection{Conjugate Synthesis}

FGF2 was genetically engineered (C78S) to contain a single surface-exposed free cysteine, Cys96, to facilitate site-specific polymer conjugation and therefore stoichiometric homodimerization. This mutation was made on a pET29c(+)hFGF-2 plasmid provided by the Helmholtz Centre for Infection Research, Braunschweig, Germany[60]. Employing E. coli host BL21(DE3), the mutant was expressed and purified as previously described.[60] The activity of the mutant was confirmed in an in vitro metabolic activity assay in HDFs, and no significant difference was observed as compared to natural FGF2. Pure mutant protein (hereby called simply "FGF2") was obtained as visualized by Western Blot (Figure 2, lane 2) with a molecular weight of 17.2 kDa measured by MALDI mass spectrometry (Figure S1). The mutation was further verified by trypsin-digestion followed by liquid chromatography-tandem mass spectrometry, and the expected peptide (GVVSIKGVSANR) showing the C78S mutation was found. 
PEG linker lengths were chosen based on the inter-cysteine distance (Cys96 of one FGF2 to Cys96 in the second FGF2) in the 2:2 FGF2:FGFR1 tetrameric complex (Figure 1), which is approximately $70 \AA$ A. Based on prior work[61-63], we hypothesized that in the active tetrameric complex the PEG would be stretched slightly from its normal random coil configuration. As a guide we considered Flory's Radius $\left(\mathrm{R}_{\mathrm{F}}=\mathrm{aN}^{0.6}\right)$ where $\mathrm{a}=$ monomer unit length and $\mathrm{N}=\#$ monomers or degree of polymerization, to estimate the random coil length of various PEGs. We also used the equation for a fully-extended polymer chain of length $\mathrm{L}=\mathrm{aN}$ to estimate the maximum possible length. We hypothesized that the best candidate would be a PEG with an $\mathrm{R}_{\mathrm{F}}<70 \AA$ and an $\mathrm{L}>70 \AA$ (both 2 and $6 \mathrm{kDa}$ PEG fit this description, Table 1). For comparison we also chose a small molecule linker, divinyl sulfone (DVS), where both $\mathrm{R}_{\mathrm{F}}$ and $\mathrm{L} \ll<70 \AA$ and a large $20 \mathrm{kDa}$ PEG control where both $\mathrm{R}_{\mathrm{F}}$ and L >> $70 \AA$ (Table 1).

Table 1. Crosslinker length based on Flory's radius of gyration and fully extended chain length.

\begin{tabular}{|l|l|l|l|l|l|}
\hline Crosslinker & $\mathbf{M W}^{*}$ & $\mathbf{a}^{\dagger}$ & $\mathbf{N}$ & $\mathbf{R}_{\mathbf{F}}^{\dagger}$ & $\mathbf{L}^{\dagger}$ \\
\hline DVS & 118 & $<10$ & 1 & $<10$ & $<10$ \\
\hline VS-PEG2k-VS & 2000 & 3.5 & 45 & 35 & 160 \\
\hline VS-PEG6k-VS & 6000 & 3.5 & 136 & 67 & 480 \\
\hline VS-PEG20k-VS & 20000 & 3.5 & 454 & 138 & 1600 \\
\hline
\end{tabular}

Site-specific conjugation can be achieved through Michael addition of nucleophilic amino acid residues to vinyl sulfone (VS) groups. By maintaining a $\mathrm{pH}$ between 7 and 9, cysteine residues can be targeted preferentially compared to the reaction to lysine or N-terminal amines,[64] and FGF2 is stable between pH 5 and 9[65]. 
Therefore PEGs (2, 6, and $20 \mathrm{kDa})$ were modified at both ends with VS according to literature procedures[66]. Since PEGylated proteins often exhibit enhanced activity due to increased stabilization or conversely can decrease activity due to steric hindrance, monoconjugated controls were synthesized. Towards that end, poly(ethylene glycol methyl ether) (mPEGs) with molecular weights of 2, 5, and $20 \mathrm{kDa}$ were modified on one end with VS.

In order to synthesize the conjugates, FGF2 was incubated with 0.5 eq. of polymer (2, 6, or $20 \mathrm{kDa}$ VS-PEG-VS, 2, 5, or $20 \mathrm{kDa}$ mPEG-VS) or small molecule crosslinker DVS in $100 \mathrm{mM}$ Tris buffer, $\mathrm{pH} 9$ at room temperature for 12 hours. A range of buffer types, pHs, polymer equivalents, times, and addition of organic solvents were screened, and in all cases the maximum yield of the desired conjugate (monoconjugate or homodimer) was obtained using the conditions described below. Although excess polymer is typically used to maximize monoconjugate yield, excess polymer resulted in multiple polymer additions, which were difficult to remove. Kang et al. also observed up to four polymer additions for monoconjugations and hypothesized that with increased time the two internal cysteines are also able to react[48]. This was avoided by using 0.5 equivalents of polymer incubated with the protein at $73 \mu \mathrm{M}$ concentration in $100 \mathrm{mM}$

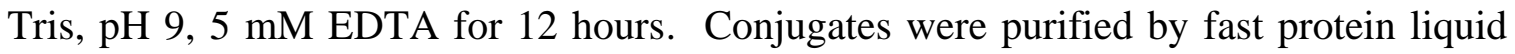
chromatography (FPLC). Pure monoconjugates and homodimers were obtained for each length PEG as visualized by western blot (Figure 2, procedure in Supplemental Information). For FGF2-PEG20k-FGF2 (Figure 2, lane 9) the homodimer appears as a smear, which is often observed with larger polymer-conjugates. 


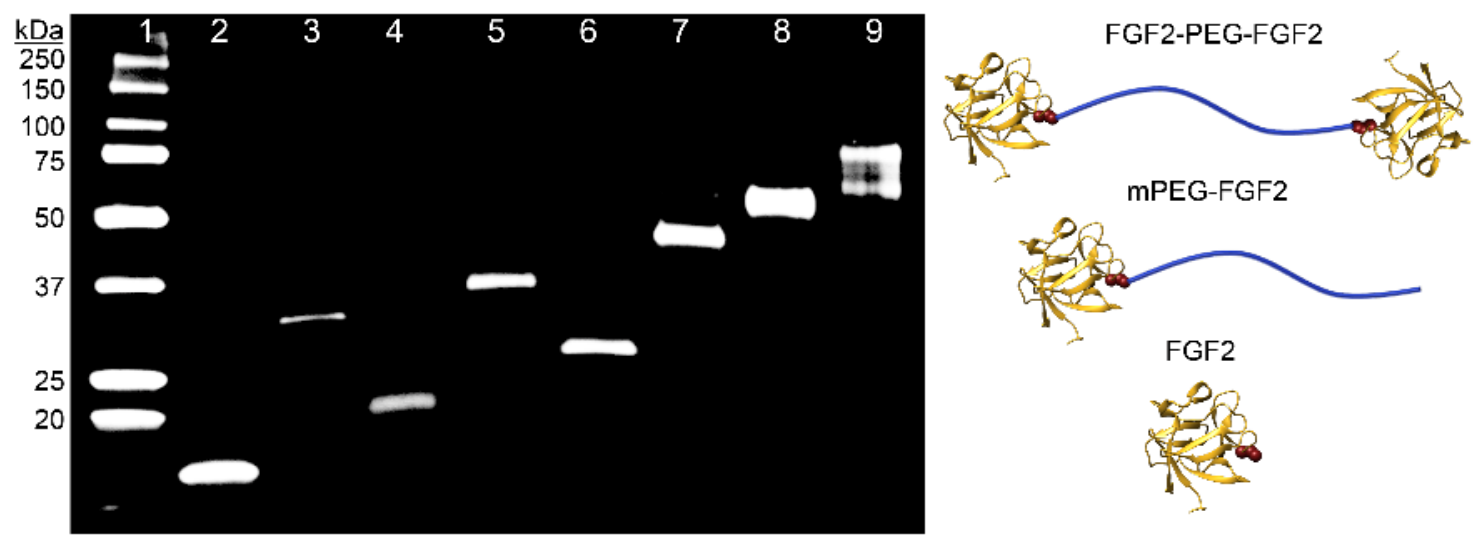

Figure 2. Western blot of purified conjugates. Lane 1: Protein Ladder; Lane 2: FGF2;

Lane 3: FGF2-VS-FGF2; Lane 4: mPEG2k-FGF2; Lane 5: FGF2-PEG2k-FGF2; Lane 6: mPEG5k-FGF2; Lane 7: FGF2-PEG6k-FGF2; Lane 8: mPEG20k-FGF2; Lane 9: FGF2-PEG20k-FGF2.

\subsection{Conjugate Screening in Metabolic activity and Migration Assays}

Efficacy of FGF2 in wound healing is often first assessed in vitro by fibroblast and endothelial cell metabolic activity (proliferation), migration, vasculogenesis, and angiogenesis[14, 67-70]. Human dermal fibroblast (HDF) metabolic activity was chosen to screen and compare the activity of all PEG-linked dimers, monoPEGylated controls, the small molecule control, and FGF2 alone. HDFs were serum and growth factor starved, followed by treatment with samples for 3 days.

FGF2-PEG2k-FGF2 induced significantly greater metabolic activity as determined by the standard CellTiter Blue assay in HDFs than all other linker lengths, all monoPEGylated controls, and free FGF2 at every concentration tested (Figure 3a). FGF2-PEG2k-FGF2 induced the most marked difference in metabolic activity at low $(0.1$ $\mathrm{ng} / \mathrm{mL}$ ) concentrations where the dimer induced $169 \%$ compared to blank media (set to 
100\%) while FGF2 alone and monoconjugate were only $118 \%$ and $131 \%$, respectively.

PEG is known to increase the stability of FGF2 thereby increasing in vitro activity,[53, $54,56]$ and likely the $2 \mathrm{kDa}$ PEG increased the stability of FGF2 in the monoconjugate. Yet the activity of the dimer was significantly higher than the monoconjugate demonstrating that dimerization, as opposed to increased stability alone, was the important factor. FGF2-PEG2k-FGF2 induced the highest metabolic activity overall, $181 \%$ compared to blank media, at $1 \mathrm{ng} / \mathrm{mL}$ while FGF2 alone induced only $144 \%$ metabolic activity at $1 \mathrm{ng} / \mathrm{mL}$. The increase in metabolic activity compared to blank plateaued at $1 \mathrm{ng} / \mathrm{mL}$ for FGF2-PEG2k-FGF2 but even with this plateau, the increased metabolic activity is greater than all other conjugates and FGF2 alone. The small molecule linked homodimer, FGF2-VS-FGF2, did stimulate significantly greater growth than FGF2 at low concentrations $(0.1 \mathrm{ng} / \mathrm{mL})$. However this increase was small, likely due to the steric restrictions of such a short linker. The fact that there was increased activity indicates that there is some flexibility in the 2:2 FGF2:FGFR tetrameric complex and indeed other modes of dimerization have been shown to be effective.[45] While FGF2-PEG6k-FGF2 did induce greater metabolic activity than FGF2 at low concentrations $(0.1$ and $1 \mathrm{ng} / \mathrm{mL})$, it did not significantly increase metabolic activity beyond that of its monoPEGylated control (mPEG5k-FGF2) indicating that the increase in activity might be due solely to the added stability induced by PEG. Again, the enhanced activity was only slightly increased (14 and 13\%, respectively) compared to FGF2 at the two lower concentrations. For FGF2-PEG20k-FGF2, a decrease in activity as compared to FGF2 was observed. FGF2-PEG20k-FGF2 induced 13\% and 18\% less metabolic activity than FGF2 at 1 and $10 \mathrm{ng} / \mathrm{mL}$, respectively. While we expected the 
longer linker to be less effective than the shorter linkers, decreased activity as compared to FGF2 was not expected. Taken together, these results supported our hypothesis that the optimal linker length was: $\mathrm{R}_{\mathrm{F}}(35 \AA)<$ inter-cysteine distance $(70 \AA)$ and $\mathrm{L}(160 \AA)>$ the inter-cysteine distance. We then tested a greater number of concentrations $(0.01,0.05$, $0.1,1,2,5,10 \mathrm{ng} / \mathrm{mL}$ ) of FGF2 and FGF2-PEG2k-FGF2 on HDF metabolic activity, to assess the lowest effective concentration (Figure 3, b). Even at $0.01 \mathrm{ng} / \mathrm{mL}$ FGF2PEG2k-FGF2 induced a 139\% increase in HDF metabolic activity as compared to $105 \%$ for FGF2. Thus, FGF2-PEG2k-FGF2 exhibited superagonist activity in the metabolic activity of HDFs, even at extremely low concentrations, making it a good target for further study.

The increased efficacy of the tethered ligands presents a fundamental question in physical chemistry that influences the design principles of this and any other dimerized ligand that acts at low concentration in vivo. A theoretical study was undertaken to address the trends in ligand activity with changing molecular weight of the tether. Previously researchers have proposed a number of mechanisms for the binding of FGF2 to its receptor. These include: (1) the "dimer first" model in which dimers form in solution facilitated by heparin/heparan sulfate proteoglycans and then bind collectively to the receptors (2:2:1 model); and (2) "dimer second" model in which monomers bind via heparin/heparan sulfate proteoglycans to membrane receptors and then form the tetrameric complex $(2: 2: 2$ model).[38, 71, 72] In our analysis, we ignore heparinmediated dimerization in solution; in effect, the polymeric tether permanently (covalently) locks monomers into dimers while in solution. Thus, we consider a simple model in which permanently tethered growth factor dimers bind to the receptor, and 
examine how changes in the length of the tether change the efficiency of binding as measured indirectly through wound healing.

The presence of the polymeric tether enhances the capture rate of the second ligand in two ways. First, upon the binding of the first ligand, a second ligand is necessarily also brought into the vicinity of the receptor (found at a typical distance of $\mathrm{N}^{1 / 2} b$ for a tether of $\mathrm{N}$ monomers and Kuhn length $b$ ). Second, the tether introduces an entropic driving force drawing the second ligand towards the receptor. This advective transport shortens the mean time to capture for this second ligand as compared to a free ligand introduced at the same distance. Excluding steric effects and treating the tether as a Gaussian coil we found that the mean time to capture depends on the polymerization index $\mathrm{N}$ as $\tau(\mathrm{N}) \sim \mathrm{N}^{3 / 2}$, showing that capture times monotonically decrease with shorter tethers, and leads to an increasing enhancement of doubly bound ligand/receptor complexes with decreasing tether length (Figure 1 Data in Brief [ref]). There we show that for a single ligand dissociation constant $K_{d}$ the effect of dimerization is to enhance the effective activity of the ligand by a factor $R>L$ so that tethered dimers at concentration c generate an equilibrium population of doubly bound receptors on the cell surface (assuming binding consistent with chemical equilibrium) as would a higher concentration of "untethered dimers" at $R_{c}$. We find $\mathrm{R}$ is a monotonically decreasing function of $\mathrm{N}$ (proportional to the molecular weight of the tether) and reaches a theoretical maximum of $R=1+\left(K_{d} / c_{m}\right)$ for a concentration $c_{m}$ of membrane-bound receptors. Thus, the effect of dimerization is most pronounced for short tethers and in the limit of a low concentration of membrane bound receptors. Details may be found in the accompanying Data in Brief.[ref] 
The validity of the Gaussian coil model is questionable in detail. The radii of gyration of the tethers range from $7 \mathrm{~nm}$ (20kDa molecular weight) to $2 \mathrm{~nm}(2 \mathrm{kDa}$ molecular weight), comparable to the size of the ligand. Thus, the tether may be strongly stretched due to steric effects and the chain may interfere with the binding between the linker and the receptor, either sterically or due to the (necessary) misalignment between the tether's anchoring point on the ligand and binding pocket. Of these effects, the strongly stretching limit implies an effective potential for the ligand to be steeper than the parabolic one resulting from the Gaussian coil assumption, suggesting our calculation of $R$ is a lower bound. The steric hindrance on doubly-bound states appears to play a role only for tethers of molecular weights smaller than $2 \mathrm{kDa}$. Finally, the misalignment of the anchor with the binding pocket should be irrelevant as long as the work to the tether between these points is smaller than thermal energy. We suspect this to be the case quite generally for all tethers long enough to analyze in terms of standard polymer dynamics since the distance between the anchoring point and the binding pocket is comparable to only a few monomer lengths. The calculation of $R$ assumes the absence of competitive binding between a dimer and multiple membrane bound receptors. We work in the limit of vanishing small receptor concentration where this is valid. The validity of this assumption should fail when the areal concentration $\tilde{c}_{m}$ of the receptors is sufficiently high that two might be found within one radius of gyration of the $R_{g}$ tether $\tilde{c}_{m} R_{g}^{2} \sim 1$.

To further assess the viability of FGF2-PEG2k-FGF2, HDF migration was assessed in a scratch assay (Figure 3, c). A scratch was made through a confluent layer of growth factor starved cells followed by the application of sample and incubation for 18 hours. Incubation time was restricted to 18 hours to ensure that differences were not due 
to proliferation. FGF2-PEG2k-FGF2 induced a slight, but significantly greater migration at the lowest concentration tested $(0.05 \mathrm{ng} / \mathrm{mL})$ resulting in $131 \%$ increase in HDF migration compared to $117 \%$ for FGF2 alone. While both FGF2 and FGF2-PEG2kFGF2 induced significantly greater migration as compared to blank at all higher concentrations, there was no significant difference between the two. These results indicate that the FGF2 dimer does not greatly enhance migration of HDFs and that metabolic activity is more strongly influenced in this cell type. 
A.
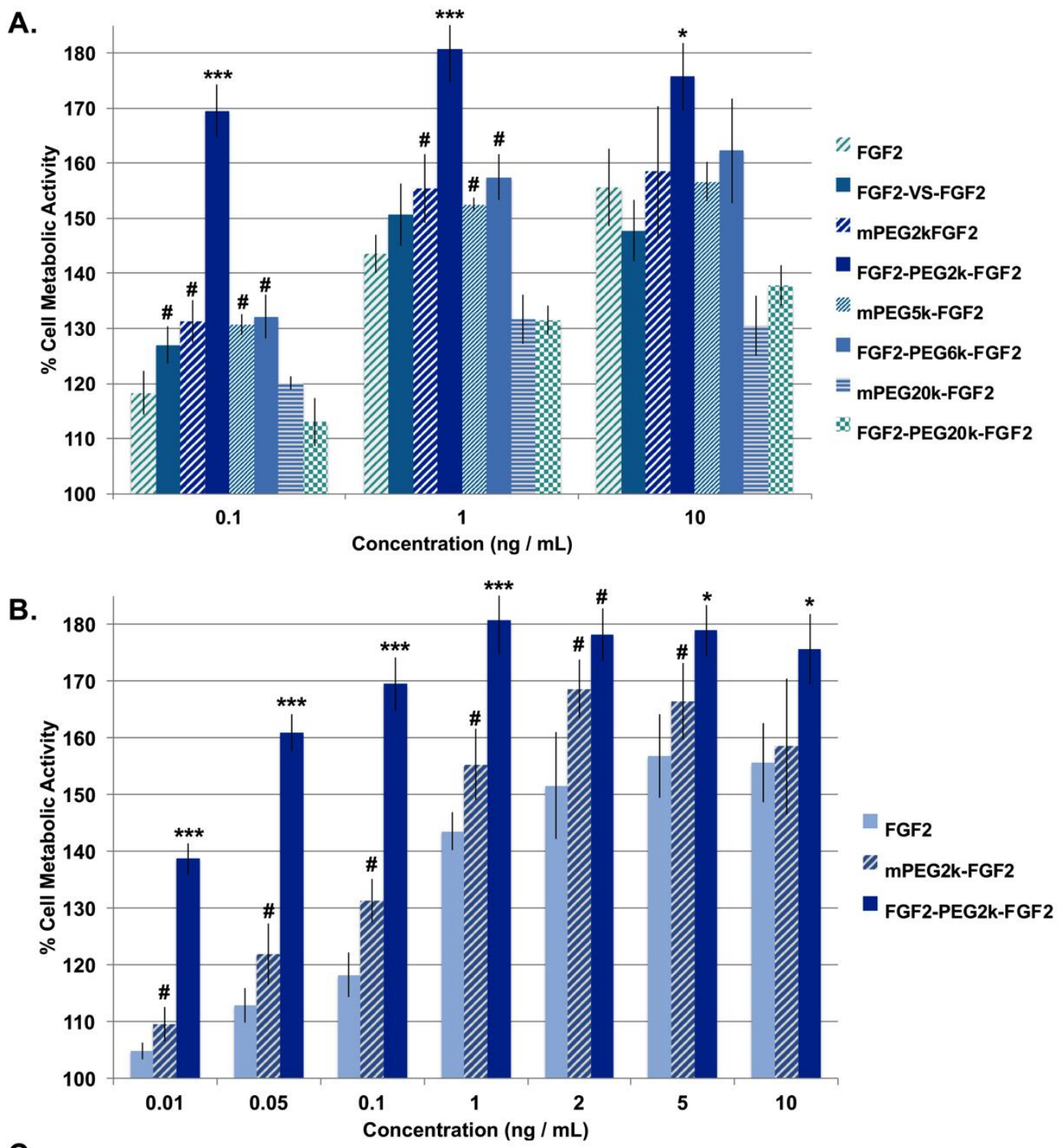

c.

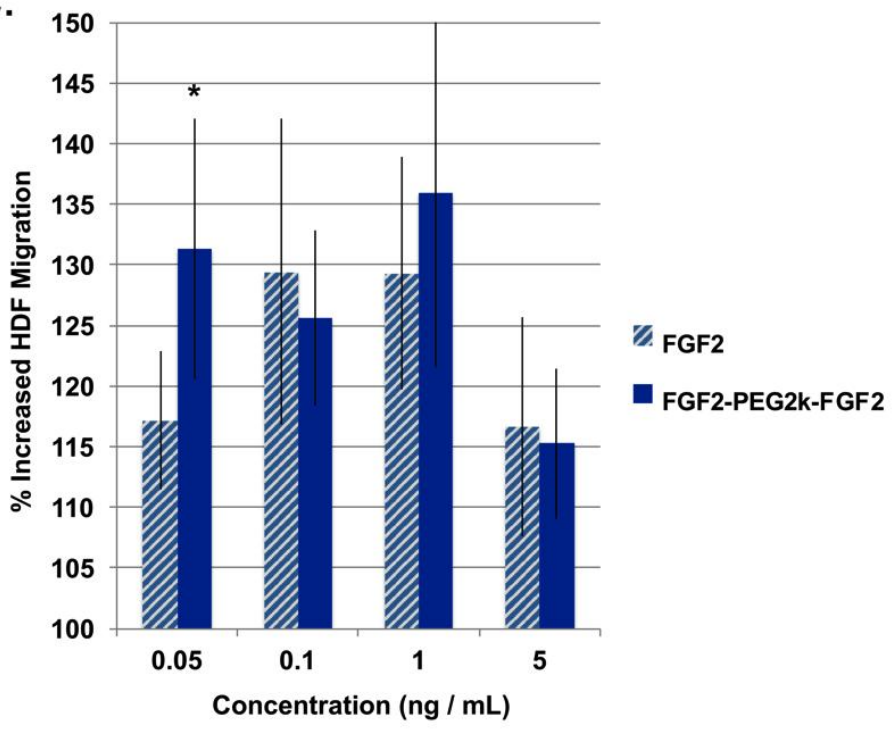


Figure 3. Screening of PEG linker-length effect on HDF metabolic activity and migration. (a) and (b) Percent metabolic activity of HDFs (mean +/- SD). All samples are normalized to blank media per treatment set $(\mathrm{n}=6)$. In $(\mathrm{b})$, bars for $0.1,1$, and 10 $\mathrm{ng} / \mathrm{mL}$ are duplicated from part (a). (c) Migration scratch assay of HDFs treated with FGF2 or FGF2-PEG2k-FGF2 for 18 hours. Each treatment was repeated 5-7 times. The distance across the scratch was measure in ImageJ in pixels and the \% increased HDF migration was calculated as $100-$ distance at $\mathrm{T} /$ distance at $\mathrm{T}_{0} * 100$. Statistical analysis was carried out using a student's t-test (c) or ANOVA + Tukey (a) and (b). \# = statistically greater than $\mathrm{FGF} 2$ control at that concentration, $\mathrm{p}<0.05 . \quad *$ or $* * *=$ statistically greater than both FGF2 and mPEG-FGF2, $\mathrm{p}<0.05$ and $\mathrm{p}<0.001$, respectively at that concentration.

Next the in vitro metabolic activity and migration of human umbilical vein endothelial cells (HUVECs) was assessed with FGF2-PEG2k-FGF2 and compared to free FGF2 (Figure 4). Since the most drastic improvements in activity occurred at lower concentrations in HDFs, we focused our test on low concentrations for HUVEC metabolic activity. FGF2-PEG2k-FGF2 significantly increased metabolic activity compared to FGF2 at low concentrations and exhibited similar activity at $1 \mathrm{ng} / \mathrm{mL}$ (Figure 4a). Specifically, FGF2-PEG2k-FGF2 increased metabolic activity as compared to FGF2 by $28 \%, 21 \%$ and $21 \%$ at $0.01,0.05$ and $0.1 \mathrm{ng} / \mathrm{mL}$, respectively. Compared to blank media, FGF2-PEG2k-FGF2 increased metabolic activity most effectively at 0.1 $\mathrm{ng} / \mathrm{mL}$, to $148 \%$ compared to blank media. HUVEC migration was investigated over a 
range of concentrations in a scratch-assay using the same protocol as described for HDFs (Figure 4b and c). FGF2-PEG2k-FGF2 significantly increased migration into the scratch compared to FGF2 at $0.01,0.05,0.1$, and $1 \mathrm{ng} / \mathrm{mL}$. The greatest increase in migration was observed at $0.1 \mathrm{ng} / \mathrm{mL}$, where HUVEC migration was increased by $163 \%$ compared to blank media for FGF2-PEG2k-FGF2 while for FGF2 it was increased by only $108 \%$. These results further indicated that FGF2-PEG2k-FGF2 was a good candidate for additional study at low concentrations.

A.

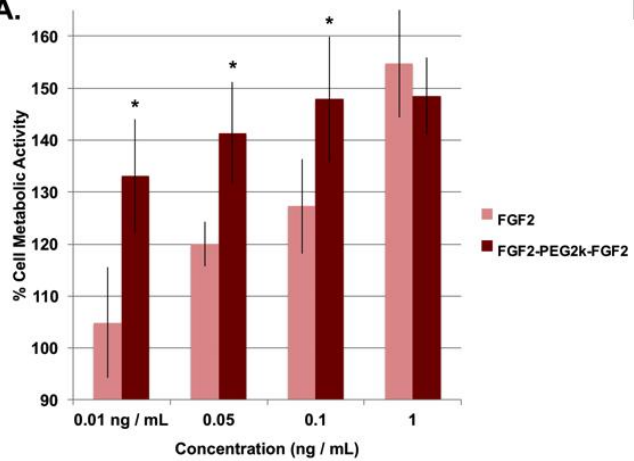

c.

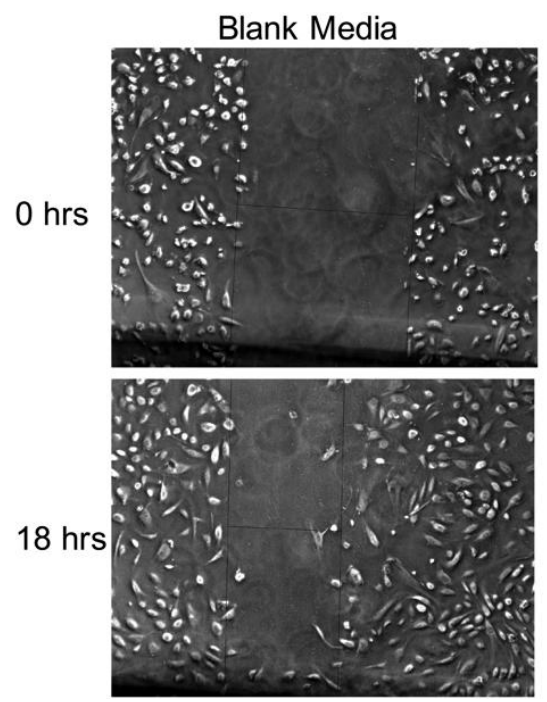

B.
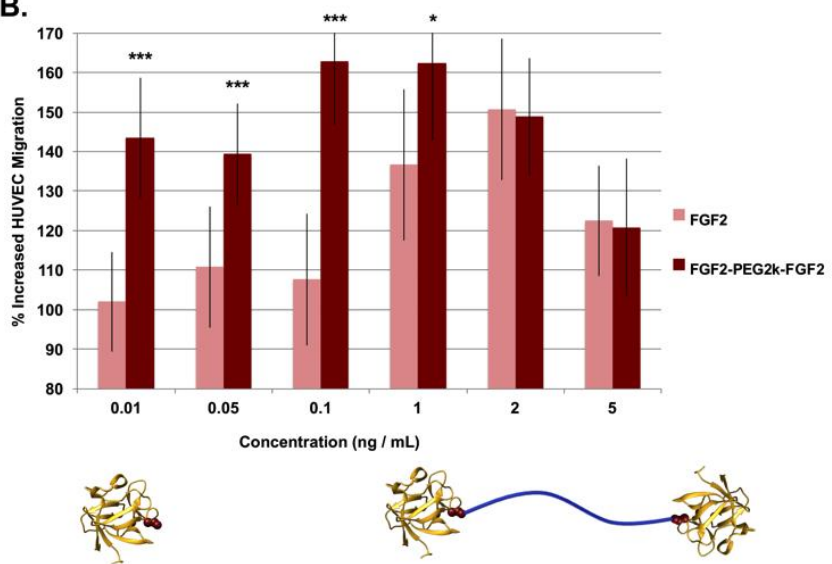

FGF2

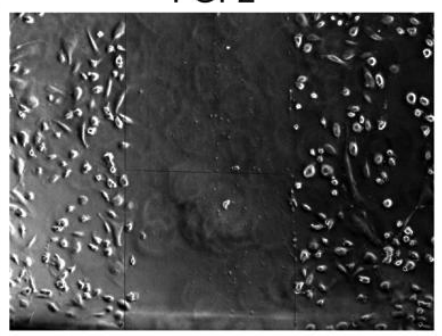

FGF2-PEG2k-FGF2

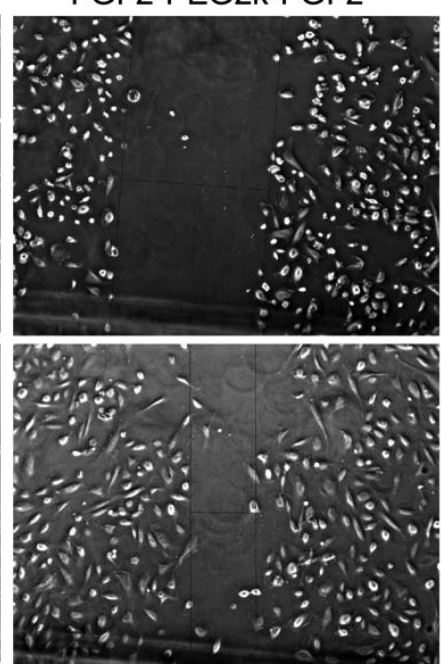

Figure 4. (a) Metabolic activity of HUVECs at various concentrations of FGF2 and

FGF2-PEG2k-FGF2. Each treatment was repeated 5-6 times and the entire study 
repeated twice. (b) Migration scratch assay of HUVECs treated with FGF2 or FGF2PEG2k-FGF2 for 18 hours. Each treatment was repeated 4-7 times and the entire study repeated twice ( $n=9-12$ total). The distance across the scratch was measured using ImageJ in pixels and the $\%$ increased migration was calculated as $100-$ distance at $\mathrm{T} /$ distance at $\mathrm{T}_{0} * 100$. For (a) and (b) all samples were normalized to blank media per treatment set and recorded as mean $+/-$ SD. . Statistical analysis was carried out using a student's ttest. $*=\mathrm{p}<0.05 . * * *=\mathrm{p}<0.001$ (c) Representative images of HUVECs $(5 \mathrm{x}$ magnification) at 18 hours and 0 hours after scratching and treatment with $0.1 \mathrm{ng} / \mathrm{mL}$ of each sample.

\subsection{FGF2-PEG2k-FGF2 Increases Angiogenesis In Vitro}

FGF2-PEG2k-FGF2 was also tested for increased angiogenesis. A rudimentary coculture assay of HDFs and HUVECs was utilized[57, 58]. HDFs were first allowed to grow to confluency before HUVECs were added with the respective experimental sample. Sample solutions were refreshed at days 3 and 6. After 10 days the cells were fixed and cord-like structures stained for CD31. FGF2-PEG2k-FGF2 induced a significant increase in the number of nodes, cord-like structures, and total length of cordlike structures compared to FGF2 at low concentrations $(0.1$ and $0.5 \mathrm{ng} / \mathrm{mL})$ and performed as well as FGF2 at higher concentrations (1, 5, and $10 \mathrm{ng} / \mathrm{mL}$ ) (Figure 5). Specifically, at $0.1 \mathrm{ng} / \mathrm{mL}$, cells treated with FGF2-PEG2k-FGF2 increased the average number of nodes by 97 , cord-like structures by 186 , and increased the total length of cord-like structures to 9 times that of FGF2. At $0.5 \mathrm{ng} / \mathrm{mL}$, FGF2-PEG2k-FGF2 increased the average number of nodes by 120 , cord-like structures by 229 , and the total 
length of the cord-like structures was increased to 4 times that of FGF2. Thus at these low concentrations, FGF2-PEG2k-FGF2 improved all evaluated aspects of angiogenesis compared to free FGF2.
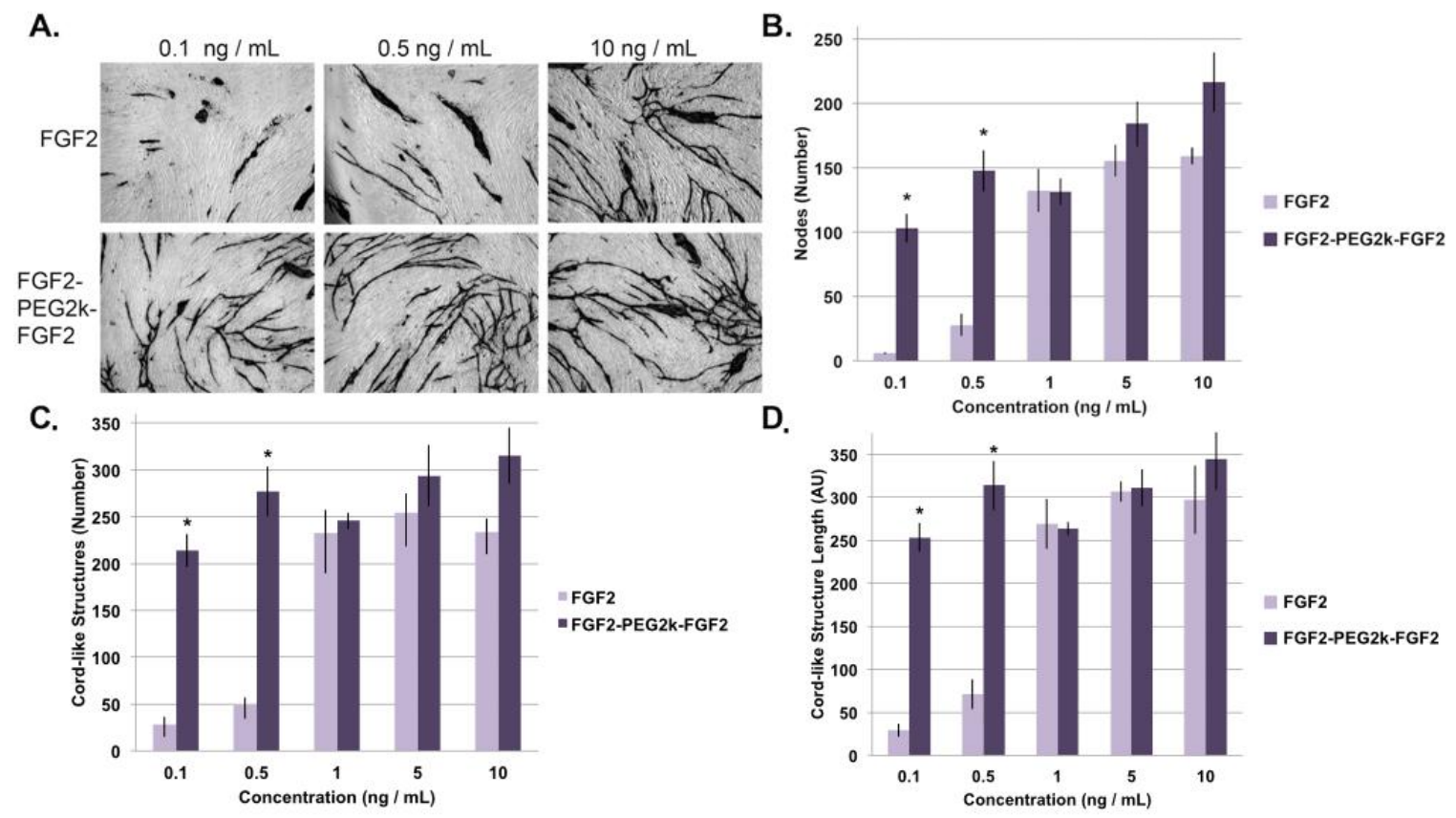

Figure 5. Effect of FGF2 and FGF2-PEG2k-FGF2 at various concentrations on angiogenesis through the co-culture of HDFs and HUVECs (n=3). (a) Representative images of select sample sets, cord-like structures stained. (b) Comparison of the number of nodes per condition / sample set. (c) Comparison of the number of cord-like structures per condition / sample set. (d) The average total cord-like structure length per image (pixels) per condition / sample set (mean +/- SD). Statistical analysis was carried out using a student's t-test. $*=\mathrm{p}<0.05$.

\subsection{FGF2-PEG2k-FGF2 Increases Granulation Tissue and Blood Vessel Density in Wounded, Diabetic TallyHo Mice}


Since FGF2-PEG2k-FGF2 significantly enhanced in vitro metabolic activity, migration, and co-culture cord-like structures, the efficacy of FGF2-PEG2k-FGF2 was investigated in vivo in a wounded mouse model. TallyHo/JngJ mice, which develop a type II diabetic phenotype, were wounded ( $8 \mathrm{~mm}$ punch biopsy) and then treated daily for 5 days with $0.02 \mu \mathrm{g}$ of FGF2, FGF2-PEG2k-FGF2 or D-PBS control. The wound closure was measured at days $0,1,4,7,10$, and 14 . There was no significant difference in wound closure among the cohorts of mice (Fig. 6a,b) as is common for this animal model and wound size[73]. In contrast, the granulation tissue area and the blood vessel density in the wound bed were both significantly greater in the FGF2-PEG2k-FGF2 treated mice than either FGF2 treated mice $(\mathrm{p}<0.05)$ or D-PBS control $(\mathrm{p}<0.01)(\mathrm{Fig}, 6 \mathrm{c}, \mathrm{d}, \mathrm{e})$. These results indicate that the low concentration of FGF2-PEG2k-FGF2 was highly effective in promoting granulation tissue and angiogenesis in the wound bed. 

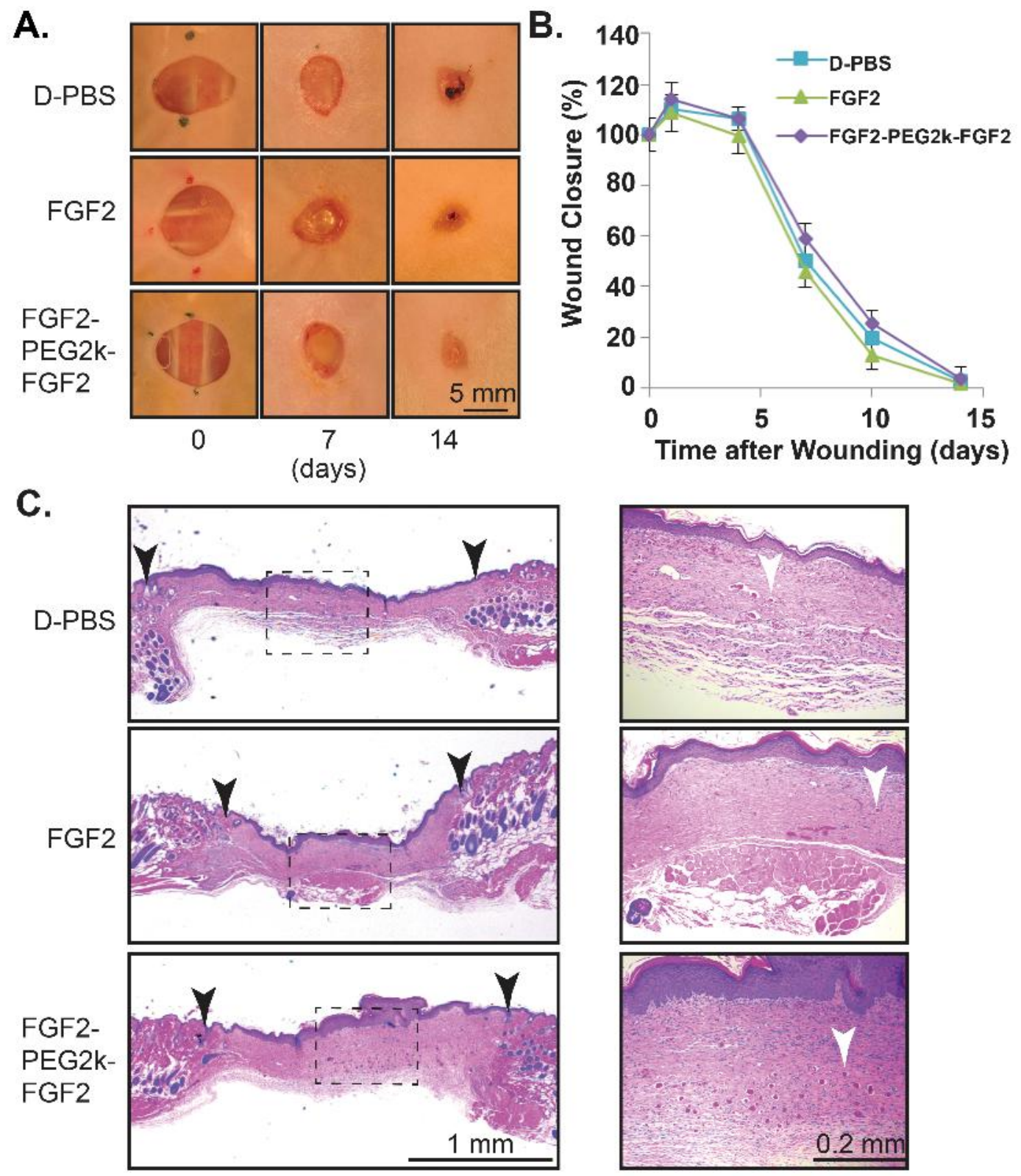

D.

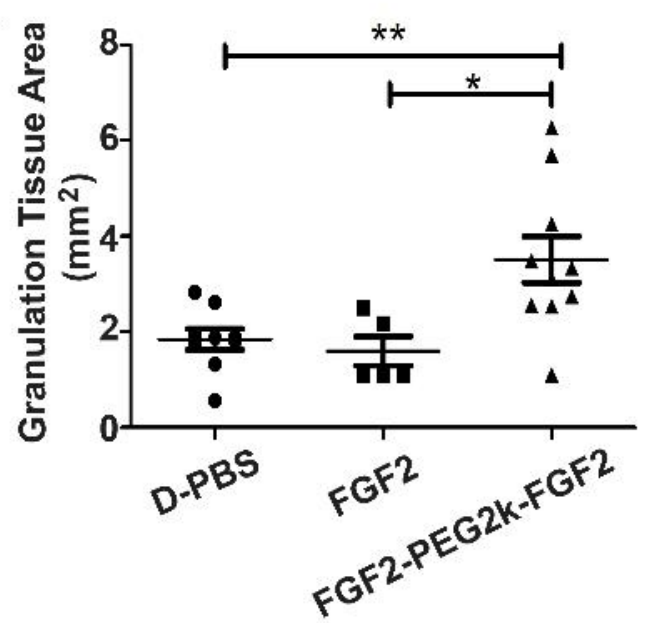

E.

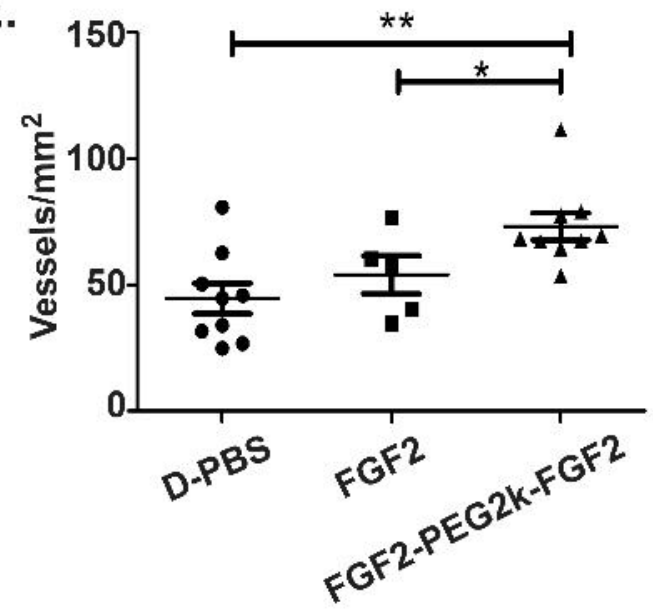


Figure 6. In vivo assessment of FGF2-PEG2k-FGF2 in diabetic wounds. Sterile wounds ( $8 \mathrm{~mm}$ punch biopsy) were performed on TallyHo/JngJ diabetic mice and the wounds were covered (Tegaderm) and treated daily for 5 days with $0.02 \mu \mathrm{g}$ of FGF2, FGF2PEG2k-FGF2 or D-PBS control. (A) Representative photographs of the skin wounds in treated diabetic wounds. (B) Mean wound area \pm s.e.m. (C) Representative histology (H\&E stained) at low magnification (left panels) and high magnification of the boxed dotted area (right panels) with black arrows indicating wound edges and white arrows indicating blood vessels. Quantitative analysis of granulation tissue area (D) and blood vessel density (E). *p<0.05, ** $<<0.01$ FGF2-PEG2k-FGF2 versus FGF2 or D-PBS (n=510/group).

\section{Discussion}

Chronic wounds represent a widespread and increasing socioeconomic problem. Depressed levels of growth factors and their receptors, including FGF2, are a main factor in non-healing wounds. Currently, advanced wound care therapies for non-healing ulcers include the use of collagen, growth factors, bioengineered skin, gene and stem cell therapy, silver products, ozone oxygen therapy, and negative pressure wound therapy[74]. We sought to improve upon the activity of FGF2 for its potential use alone or in combination with advanced wound care therapies. Our studies show that FGF2PEG-FGF2, where the tether length is $2 \mathrm{kDa}$, represents a promising candidate for increasing the granulation tissue and blood vessel density during wound healing.

Utilizing available knowledge of FGF2 activity and its crystal structure with its receptor and theoretical investigation, we were able to rationally design a protein more 
active than the native one in promoting fibroblast metabolic activity and endothelial cell metabolic activity and migration. Mutation of the protein was undertaken in order to obtain a single reactive cysteine for modification, spatially separate from residues required for receptor binding and protein activity. Homodimerization of the protein was achieved through Michael addition to bis-reactive linear PEG tethers, varying the length based on both the spatial restrictions informed by the active protein-receptor crystal structure, as well as taking in to account PEG flexibility and stretch. The best linkerlength in this work was determined to be $2 \mathrm{kDa}$ PEG. Analytic calculations based on a Gaussian coil model of the tether suggest that shortening the tether down to this distance should be beneficial. At such short distances, however, a reasonable model must account for steric interactions between the ligands and between the chain and the ligands - see Data in Brief [ref], for details. The simplicity of synthesis and purification as well as the effectiveness of the current model represents a viable candidate for further studies.

FGF2-PEG2k-FGF2 showed enhanced metabolic activity, migration, and formation of cord-like structures in an angiogenesis co-culture assay in vitro, as well as enhanced granulation tissue and blood vessel density in diabetic mice in vivo, all at low effective concentrations as compared to unmodified FGF2. Proliferation of HDF and HUVEC cells is often utilized as a first test to determine the in vitro efficacy of FGF2[14, 67-70] and the dimer performed far better than the native protein in the cell metabolic assay. Migration is another measure of the ability of the growth factor to potentially elicit a response in wound healing since migration of cells into a wound is an important factor. The dimer produced much higher migration of HUVEC cells in a scratch assay. In addition, the dimer produced a greater number of cord-like structures with longer 
lengths and more nodes than the native protein in a basic in vitro co-culture angiogenesis assay. These assays, although simple in nature, have limitations. Two-dimensional assays are useful to analyze the proliferation, migration, and migration of single cells.[77] However, these assays have been shown to have significant differences compared to three dimensional systems and therefore are not necessarily relevant to wound healing in vivo, which involve numerous processes occurring simultaneously.[78] The co-culture assay is simple to carry out, but does not provide information about tubular structures or perfusion through the structures as does the more sophisticated assays. Thus, in vivo experiments were carried out in a wounded diabetic mouse model. The results show that granulation tissue formation and blood vessel number is increased compared to FGF2. Since granulation tissue results from fibroblast proliferation and blood vessel number increase is likely due to angiogenesis,[79] the in vivo results confirm the in vitro ones.

A previous report demonstrated that a recombinantly engineered dimeric FGF2 had higher proliferation activity in smooth muscle cells and was able to partially rescue activity in a serum starved media at a slightly lower concentration than the monomer alone.[45] Our data is not directly comparable to this reference for several reasons. First a different cell type was used for the proliferation (cell metabolic activity) assay and for HUVEC cells we utilized much lower concentrations. In addition for the latter, although both examples were serum starved, we added the protein to EGF. So we see enhancement above normal activity, not a partial rescue of activity as in the case of the recombinant dimer. Yet in our case the approach is likely simpler because it is chemically dimerized rather than requiring a new recombinant synthesis and folding methodology. 
While increased rate of closure was not observed in vivo, this is likely due to the extremely low concentrations tested and the animal model used (diabetic mice heal by contraction in addition to reepitheliazation). This has been observed in other studies: For instance, Orgill and coworkers tested wound closure in C57BL/KsJ db+/db+ mice, and found no increase in wound closure when $1.5 \mathrm{~cm}^{2}$ wounds were treated with $10 \mu \mathrm{g}$ of PDGF each day for five days, but did see an increase in granulation tissue[73]. Hubbell and coworkers tested genetically modified superagonists of vascular endothelial growth factor (VEGF), PDGF, and bone morphogenetic protein-2 at low concentrations (200 ng/wound) and found that the modified growth factors increased granulation tissue formation compared to no treatment, while unmodified growth factors induced no increase at this concentration[80]. Therefore increased granulation tissue area and angiogenesis indicates better blood supply and a more fertile wound bed preparation, both favorable properties in wound healing. This could translate to faster wound healing in higher order animals, and this will be tested in future work.

This work does show that PEG dimerization of the FGF2 results in enhanced activity at low concentrations. Low concentrations are advantageous to avoid superphysiologic doses often used for growth factors, that can significantly increase the costs of a therapeutic.[75] However, growth factors, particularly FGF2, are known to be unstable.[81, 82] Although PEG does increase stability of proteins including FGF2,[53, $54,56]$ further stabilization of the protein through release from a heparinized matrix or by using a heparin mimicking polymer as a tether would be advantageous. We recently reported a heparin mimicking polymer conjugate that stabilizes FGF2 to therapeutically relevant conditions, including elevated temperatures and treatment with proteolytic 
enzymes.[83] What was learned from that work could be readily combined with the dimer strategy reported herein to produce a superagonist growth factor effective at lower concentrations that is also stable to a variety of stressors, and this work is ongoing.

\section{Conclusions}

We have developed a superagonist FGF2 by site-specific dimerization utilizing $2 \mathrm{kDa}$ PEG. The ideal linker length was determined empirically, with the most effective linker being that with a Flory's radius closest to the FGF2:FGFR tetramer inter-cysteine distance. Analytic calculations based on a Gaussian coil model were employed to understand the effect of linker length on receptor dimerization and activity. FGF2PEG2k-FGF2 exhibited superior activity compared to FGF2 for both metabolic activity and migration in a scratch assay in fibroblasts and human umbilical vein endothelial cells as well as exhibiting improved cord-like structures in a co-culture of the two cell lines, all at very low concentrations. Finally, FGF2-PEG2k-FGF2 induced increased granulation tissue and blood vessel density in the wound bed of diabetic mice. Overall, the data suggests that this FGF2 dimer is a promising candidate for increasing the quality of the wound bed in wound healing.

\section{Acknowledgments}

This work was funded by NIH NIBIB (R01EB013674) and NIH NIGMS (R01GM103479 to JAL). CD thanks the 2014 Cram Fellowship for additional funding. The authors thank the Helmholtz Centre for Infection Research, Braunschweig, Germany 
for providing the pET29c(+)hFGF-2 plasmid and Dr. Mark Arbing (UCLA Protein Expression Technology Center of the UCLA/DOE Institute for Genomics and Proteomics) for mutagenesis of the provided plasmid. CD thanks Andrew Pati Ah Young for his genuine interest in this work and for valuable scientific discussion. AJL and LS acknowledge partial support from NSF-DMR-1309188.

\section{References}

[1] Brem H, Tomic-Canic M. Cellular and molecular basis of wound healing in diabetes. J. Clin. Invest. 2007;117:1219-22.

[2] Jiang L, Dai Y, Cui F, Pan Y, Zhang H, Xiao J, et al. Expression of cytokines, growth factors and apoptosis-related signal molecules in chronic pressure ulcer wounds healing. Spinal Cord. 2014;52:145-51.

[3] Demidova-Rice TN, Hamblin MR, Herman IM. Acute and impaired wound healing: pathophysiology and current methods for drug delivery, part 1: Normal and chronic wounds: biology, causes, and approaches to care. Adv. Skin Wound Care. 2012;25:30414.

[4] Shaw JE, Sicree RA, Zimmet PZ. Global estimates of the prevalence of diabetes for 2010 and 2030. Diabetes Res. Clin. Prac. 2010;87:4-14.

[5] Bikfalvi A, Klein S, Pintucci G, Rifkin DB. Biological roles of fibroblast growth factor-2. Endocr. Rev. 1997;18:26-45.

[6] Akita S, Akino K, Hirano A. Basic fibroblast growth factor in scarless wound healing. Adv. Wound Care. 2013;2:44-9. 
[7] Bhang SH, Kim JH, Yang HS, La WG, Lee TJ, Sun AY, et al. Combined delivery of heme oxygenase-1 gene and fibroblast growth factor-2 protein for therapeutic angiogenesis. Biomaterials. 2009;30:6247-56.

[8] Chen WC, Lee BG, Park DW, Kim K, Chu H, Kim K, et al. Controlled dual delivery of fibroblast growth factor-2 and Interleukin-10 by heparin-based coacervate synergistically enhances ischemic heart repair. Biomaterials. 2015;72:138-51.

[9] Cui Y, Lu C, Meng D, Xiao Z, Hou X, Ding W, et al. Collagen scaffolds modified with CNTF and bFGF promote facial nerve regeneration in minipigs. Biomaterials. 2014;35:7819-27.

[10] Nillesen ST, Geutjes PJ, Wismans R, Schalkwijk J, Daamen WF, van Kuppevelt TH. Increased angiogenesis and blood vessel maturation in acellular collagen-heparin scaffolds containing both FGF2 and VEGF. Biomaterials. 2007;28:1123-31.

[11] Lederman RJ, Mendelsohn FO, Anderson RD, Saucedo JF, Tenaglia AN, Hermiller $\mathrm{JB}$, et al. Therapeutic angiogenesis with recombinant fibroblast growth factor-2 for intermittent claudication (the TRAFFIC study): A randomised trial. Lancet. 2002;359:2053-8.

[12] Simons M, Annex BH, Laham RJ, Kleiman N, Henry T, Dauerman H, et al. Pharmacological treatment of coronary artery disease with recombinant fibroblast growth factor-2: double-blind, randomized, controlled clinical trial. Circulation. 2002;105:78893.

[13] Olympus Biotech Corporation. The TRAfermin in neuropathic diabetic food ulcer study - southern Europe the TRANS-south study. In: ClinicalTrials.gov [Internet]. Bethesda (MD): National Library of Medicine (US). 2000-[cited 2015 Dec 04]. Available 
from: https://www.clinicaltrials.gov/ct2/show/NCT01217463 NLM Identifier: NCT0121746

[14] Grazul-Bilska AT, Luthra G, Reynolds LP, Bilski JJ, Johnson ML, Adbullah SA, et al. Effects of basic fibroblast growth factor (FGF-2) on proliferation of human skin fibroblasts in type II diabetes mellitus. Exp. Clin. Endocrinol. Diabetes. 2002;110:17681.

[15] Aviles RJ, Annex BH, Lederman RJ. Testing clinical therapeutic angiogenesis using basic fibroblast growth factor (FGF-2). Br. J. Pharmacol. 2003;140:637-46.

[16] Turner N, Grose R. Fibroblast growth factor signalling: from development to cancer. Nat. Rev. Cancer. 2010;10:116-29.

[17] Benjamin H, Chai L, Findeis MA, Goodwin W, Hundal A, Israel DI, et al. (Praecis Pharmaceuticals Inc., USA). Peptide compounds useful for modulating FGF receptor activity. WO Patent PCT/US97/21070, Publication date May 22, 1998.

[18] Ballinger MD, Shyamala V, Forrest LD, Deuter-Reinhard M, Doyle LV, Wang JX, et al. Semirational design of a potent, artificial agonist of fibroblast growth factor receptors. Nat. Biotechnol. 1999;17:1199-204.

[19] Tassi E, Al-Attar A, Aigner A, Swift MR, McDonnell K, Karavanov A, et al. Enhancement of fibroblast growth factor (FGF) activity by an FGF-binding protein. J. Biol. Chem. 2001;276:40247-53.

[20] Yayon A, Rom E, Chumakov I, Blumenstein S. (Prochon Biotech Ltd., USA). FGF2 variants having $\mathrm{N}$-terminal deletions and increased receptor selectivity and uses thereof. US Patent Number 12/443,638, Publication date February 24, 2015. 
[21] Springer BA, Pantoliano MW, Sharp CM. (3-Dimensional Pharmaceuticals, inc., USA). Analogs of human basic fibroblast growth factor mutated at one or more of the positions glutamate 89, aspartate 101 or leucine 137. US Patent Number 09/220,077, Publication date August 14, 2001.

[22] Bogin O, Yayon A. (ProChon Biotech Ltd., USA). FGF variants and methods for use thereof. WO Patent Number PCT/IL2003/000379, Publication date November 20, 2003.

[23] Davis JC, Venkataraman G, Shriver Z, Raj PA, Sasisekharan R. Oligomeric selfassociation of basic fibroblast growth factor in the absence of heparin-like glycosaminoglycans. Biochem. J. 1999;341:613-20.

[24] Venkataraman G, Shriver Z, Davis JC, Sasisekharan R. Fibroblast growth factors 1 and 2 are distinct in oligomerization in the presence of heparin-like glycosaminoglycans. Proc. Natl. Acad. Sci. U.S.A. 1999;96:1892-7.

[25] Platonova N, Miquel G, Chiu L-Y, Taouji S, Moroni E, Colombo G, et al. Dimerization capacities of FGF2 purified with or without heparin-affinity chromatography. PLoS One. 2014;9:e110055.

[26] Rudenko O, Tkach V, Berezin V, Bock E. Effects of FGF receptor peptide agonists on animal behavior under normal and pathological conditions. Neurosci. Res. 2010;68:35-43.

[27] Li S, Christensen C, Kohler LB, Kiselyov VV, Berezin V, Bock E. Agonists of fibroblast growth factor receptor induce neurite outgrowth and survival of cerebellar granule neurons. Dev. Neurobiol. 2009;69:837-54. 
[28] Plotnikov AN, Schlessinger J, Hubbard SR, Mohammadi M. Structural basis for FGF receptor dimerization and activation. Cell. 1999;98:641-50.

[29] Schlessinger J, Plotnikov AN, Ibrahimi OA, Eliseenkova AV, Yeh BK, Yayon A, et al. Crystal structure of a ternary FGF-FGFR-heparin complex reveals a dual role for heparin in FGFR binding and dimerization. Mol. Cell. 2000;6:743-50.

[30] Marianayagam NJ, Sunde M, Matthews JM. The power of two: Protein dimerization in biology. Trends Biochem. Sci. 2004;29:618-25.

[31] Matthews J, Sunde M. Dimers, Oligomers, Everywhere. Matthews J, editor. In: Protein dimerization and oligomerization in biology: Springer New York; 2012. p. 1-18.

[32] Krueger AT, Kroll C, Sanchez E, Griffith LG, Imperiali B. Tailoring chimeric ligands for studying and biasing ErbB receptor family interactions. Angew. Chem. Int. Ed. 2014;53:2662-6.

[33] Kuhl PR, Griffith-Cima LG. Tethered epidermal growth factor as a paradigm for growth factor-induced stimulation from the solid phase. Nat. Med. 1996;2:1022-27.

[34] Thomas TP, Shukla R, Kotlyar A, Liang B, Ye JY, Norris TB, et al. Dendrimer-epidermal growth factor conjugate displays superagonist activity. Biomacromolecules. 2008;9:603-9.

[35] Jeppesen C, Wong JY, Kuhl TL, Israelachvili JN, Mullah N, Zalipsky S, et al. Impact of polymer tether length on multiple ligand-receptor bond formation. Science. 2001;293:465-8.

[36] Kramer RH, Karpen JW. Spanning binding sites on allosteric proteins with polymerlinked ligand dimers. Nature. 1998;395:710-13. 
[37] Green NS, Reisler E, Houk KN. Quantitative evaluation of the lengths of homobifunctional protein cross-linking reagents used as molecular rulers. Protein Sci. 2001;10:1293-304.

[38] Ornitz DM, Yayon A, Flanagan JG, Svahn CM, Levi E, Leder P. Heparin is required for cell-free binding of basic fibroblast growth-factor to a soluble receptor and for mitogenesis in whole cells. Mol. Cell. Biol. 1992;12:240-7.

[39] Ishihara M, Ono K. Structure and function of heparin and heparan sulfate; Heparinoid library and modification of FGF-activities. Trends in Glycosci. Glyc. 1998;10:223-33.

[40] Ishihara M, Tyrrell DJ, Stauber GB, Brown S, Cousens LS, Stack RJ. Preparation of affinity-fractionated, heparin-derived oligosaccharides and their effects on selected biological-activities mediated by basic fibroblast growth factor. J. Biol. Chem. 1993;268:4675-83.

[41] Herr AB, Ornitz DM, Sasisekharan R, Venkataraman G, Waksman G. Heparininduced self-association of fibroblast growth factor-2 - Evidence for two oligomerization processes. J. Biol. Chem. 1997;272:16382-9.

[42] Moy FJ, Safran M, Seddon AP, Kitchen D, Bohlen P, Aviezer D, et al. Properly oriented heparin-decasaccharide-induced dimers are the biologically active form of basic fibroblast growth factor. Biochem. 1997;36:4782-91.

[43] Waksman G, Herr AB. New insights into heparin-induced FGF oligomerization. Nat. Struct. Biol. 1998;5:527-30. 
[44] Safran M, Eisenstein M, Aviezer D, Yayon A. Oligomerization reduces heparin affinity but enhances receptor binding of fibroblast growth factor 2. Biochem. J. 2000;345:107-13.

[45] Kwan C-P, Venkataraman G, Shriver Z, Raman R, Liu D, Qi Y, et al. Probing fibroblast growth factor dimerization and role of heparin-like glycosaminoglycans in modulating dimerization and signaling. J. Biol. Chem. 2001;276:23421-9.

[46] Pelegri-O’Day EM, Lin E-W, Maynard HD. Therapeutic protein-polymer conjugates: advancing beyond PEGylation. J. Am. Chem. Soc. 2014;136:14323-32.

[47] Spicer CD, Davis BG. Selective chemical protein modification. Nat. Commun. 2014;5: 4740 .

[48] Kang CE, Tator CH, Shoichet MS. Poly(ethylene glycol) modification enhances penetration of fibroblast growth factor 2 to injured spinal cord tissue from an intrathecal delivery system. J. Controlled Release. 2010;144:25-31.

[49] Lappi DA, Matsunami R, Martineau D, Baird A. Reducing the heterogeneity of chemically conjugated targeted toxins: homogeneous basic FGF-saporin. Anal. Biochem. $1993 ; 212: 446-51$.

[50] Alconcel SNS, Baas AS, Maynard HD. FDA-approved poly(ethylene glycol)-protein conjugate drugs. Polym. Chem. 2011;2:1442-8.

[51] Knop K, Hoogenboom R, Fischer D, Schubert US. Poly(ethylene glycol) in Drug delivery: pros and cons as well as potential alternatives. Angew. Chem. Int. Ed. 2010;49:6288-308. 
[52] Huang Z, Ye C, Liu Z, Wang X, Chen H, Liu Y, et al. Solid-phase N-terminus PEGylation of recombinant human fibroblast growth factor 2 on heparin-sepharose column. Bioconjugate Chem. 2012;23:740-50.

[53] Wu XP, Li X, Zeng YY, Zheng Q, Wu S. Site-directed PEGylation of human basic fibroblast growth factor. Protein Express. Purif. 2006;48:24-7.

[54] Hadadian SS, D. N.; Mirzahoseini, H.; Shokrgozar, M. A.; Bouzari, S.; Sepahi, M. Stability and biological activity evaluations of PEGylated human basic fibroblast growth factor. Adv. Biomed. Res. 2015;4:176.

[55] Wu X, Liu X, Xiao Y, Huang Z, Xiao J, Lin S, et al. Purification and modification by polyethylene glycol of a new human basic fibroblast growth factor mutanthbFGF(Ser25,87,92). J. Chromatogr. A. 2007;1161:51-5.

[56] Zhu G, Chen G, Shi L, Feng J, Wang Y, Ye C, et al. PEGylated rhFGF-2 conveys long-term neuroprotection and improves neuronal function in a rat model of Parkinson's Disease. Mol. Neurobiol. 2015;51:32-42.

[57] Hetheridge C, Mavria G, Mellor H. Uses of the in vitro endothelial-fibroblast organotypic co-culture assay in angiogenesis research. Biomedical Soc. Trans. 2011;39: 1597-600.

[58] Bishop ET, Bell GT, Bloor S, Broom IJ, Hendry NK, Wheatley DN. An in vitro model of angiogenesis: Basic features. Angiogenesis. 1999;3:335-44.

[59] Avitabile S, Odorisio T, Madonna S, Eyerich S, Guerra L, Eyerich K, et al. Interleukin-22 promotes wound repair in diabetes by improving keratinocyte pro-healing functions. J. Invest. Dermatol. 2015;135: 2862-70. 
[60] Chen R, John J, Lavrentieva A, Müller S, Tomala M, Zhao Y, et al. Cytokine production using membrane adsorbers: Human basic fibroblast growth factor produced by Escherichia coli. Eng. Life Sci. 2012;12:29-38.

[61] Linegar KL, Adeniran AE, Kostko AF, Anisimov MA. Hydrodynamic radius of polyethylene glycol in solution obtained by dynamic light scattering. Colloid J. 2010;72:279-81.

[62] Emilsson G, Schoch RL, Feuz L, Höök F, Lim RY, Dahlin AB. Strongly stretched protein resistant poly(ethylene glycol) brushes prepared by grafting-to. ACS Appl. Mater. Interfaces. 2015;7:7505-15.

[63] Lu Y, Harding SE, Turner A, Smith B, Athwal DS, Grossmann JG, et al. Effect of PEGylation on the solution conformation of antibody fragments. J. Pharm. Sci. 2008;97:2062-79.

[64] Morpurgo M, Veronese FM, Kachensky D, Harris JM. Preparation and characterization of poly(ethylene glycol) vinyl sulfone. Bioconjugate Chem. 1996;7:3638.

[65] Vemuri S, Beylin I, Sluzky V, Stratton P, Eberlein G, Wang YJ. The stability of bFGF against thermal denaturation. J. Pharm. Pharmacol. 1994;46:481-6.

[66] Lutolf MP, Hubbell JA. Synthesis and physicochemical characterization of endlinked poly(ethylene glycol)-co-peptide hydrogels formed by Michael-type addition. Biomacromolecules. 2003;4:713-22.

[67] Singer AJ, Clark RAF. Cutaneous wound healing. N. Engl. J. Med. 1999;341:73846. 
[68] Makino T, Jinnin M, Muchemwa FC, Fukushima S, Kogushi-Nishi H, Moriya C, et al. Basic fibroblast growth factor stimulates the proliferation of human dermal fibroblasts via the ERK1/2 and JNK pathways. Br. J. Dermatol. 2010;162:717-23.

[69] van Horssen R, Galjart N, Rens JAP, Eggermont AMM, ten Hagen TLM. Differential effects of matrix and growth factors on endothelial and fibroblast motility: Application of a modified cell migration assay. J. Cell. Biochem. 2006;99:1536-52.

[70] Giraux J-L, Matou S, Bros A, Tapon-Bretaudière J, Letourneur D, Fischer A-M. Modulation of human endothelial cell proliferation and migration by fucoidan and heparin. Eur. J. Cell Biol. 1998;77:352-9.

[71] Mohammadi M, Olsen SK, Goetz R. A protein canyon in the FGF-FGF receptor dimer selects from an a la carte menu of heparan sulfate motifs. Curr. Opin. Structural Biol. 2005;15:506-16.

[72] Mohammadi M, Olsen SK, Ibrahimi OA. Structural basis for fibroblast growth factor receptor activation. Cytokine Growth Factor Rev. 2005;16:107-37.

[73] Chan RK, Liu PH, Pietramaggiori G, Ibrahim SI, Hechtman HB, Orgill DP. Effect of recombinant platelet-derived growth factor (Regranex $\left.{ }^{\circledR}\right)$ on wound closure in genetically diabetic mice. J. Burn Care Res. 2006;27:202-5.

[74] Yazdanpanah L, Nasiri M, Adarvishi S. Literature review on the management of diabetic foot ulcer. World J. Diabetes. 2015;6:37-53.

[75] Greer N, Foman N, Dorrian J, et al. Advanced wound care therapies for non-healing diabetic, venous, and arterial ulcers: A Systemic Review. Department of Veterans Affairs, Washington DC, November 2012. 
[76] Papanas D, Maltezos E. Benefit-risk Assessment of becaplermin in the treatment of diabetic foot ulcers. Drug Saf. 2010;33:455-61.

[77] Safferling K, Sutterlin T, Westphal K, Ernst C, Breuhahn K, James M, et al. Wound healing revised: a novel reepithelialization mechanism revealed by in vitro and in silico models. J. Cell Biol. 2013;203:691-709.

[78] Ali N, Hosseini M, Vainio S, Taieb A, Cario-Andre M, Rezvani HR. Skin equivalents: skin from reconstructions as models to study skin development and diseases. Br. J. Dermatol. 2015;173:391-403.

[79] Häkkinen L, Larjava H, Koivisto L. Granulation tissue formation and remodeling. Oral Wound Healing: John Wiley \& Sons, Ltd.; 2012. p. 125-73.

[80] Martino MM, Briquez PS, Güç E, Tortelli F, Kilarski WW, Metzger S, et al. Growth factors engineered for super-affinity to the extracellular matrix enhance tissue healing. Science. 2014;343:885-8.

[81] Edelman ER, Mathiowitz E, Langer R, Klagsbrun M. Controlled and modulated release of basic fibroblast growth-factor. Biomaterials. 1991;12:619-26.

[82] Whalen GF, Shing Y, Folkman J. The fate of intravenously administered bFGF and the effect of heparin. Growth Factors. 1989;1:156-64.

[83] Nguyen TH, Kim SH, Decker CG, Wong DY, Loo JA, Maynard HD. A heparinmimicking polymer conjugate stabilizes basic fibroblast growth factor. Nat. Chem. 2013;5:221-7. 